\title{
Solid State NMR Characterization of Complex Metal Hydrides systems for Hydrogen Storage Applications
}

\author{
Son-Jong Hwang ${ }^{1, *}$, Robert C. Bowman, Jr. ${ }^{2}$, Chul Kim ${ }^{1,3}$, \\ Jason A. Zan', Joseph W. Reiter ${ }^{2}$ \\ ${ }^{1}$ Division of Chemistry and Chemical Engineering, California Institute of Technology, \\ Pasadena, California 91125, USA. \\ ${ }^{2}$ Jet Propulsion Laboratory, California Institute of Technology, Pasadena, Californa, 91109-8099, USA. \\ ${ }^{3}$ Department of Chemistry, Hannam University, Daejon 305-811, Republic of Korea \\ *Corresponding author: \\ Son-Jong Hwang, E-mail: sonjong@cheme.caltech.edu.
}

From 2011 International Symposium on Analytical Science and Technology (ISAST)

Daejeon, Republic of Korea, 15-17 November, 2011

\begin{abstract}
Solid state NMR is widely applied in studies of solid state chemistries for hydrogen storage reactions. Use of ${ }^{11} \mathrm{~B}$ MAS NMR in studies of metal borohydrides $\left(\mathrm{BH}_{4}\right)$ is mainly focused, revisiting the issue of dodecaborane formation and observation of ${ }^{11} \mathrm{~B}\left\{{ }^{1} \mathrm{H}\right\}$ Nuclear Overhauser Effect.
\end{abstract}

Key words: hydrogen storage; solid state ${ }^{11} \mathrm{~B}\left\{{ }^{1} \mathrm{H}\right\}$ NOE; complex metal hydrides; dodecaborane.

\section{Introduction}

Complex metal hydrides, light metal based in particular, have been intensively investigated in $R \& D$ for hydrogen storage materials [1,2]. Aluminum hydrides $\left(\mathrm{AlH}_{4}\right)$, borohydrides $\left(\mathrm{BH}_{4}\right)$, and amides $\left(\mathrm{NH}_{2}\right)$, and their combinations have been under systematic tests for de/rehydrogenation reactions, mostly in high temperature and pressure conditions. Understanding of their reaction mechanisms required significant efforts on identification of reaction intermediates and products. Along with other crystallographic methods, application of solid state NMR has provided a great deal of valuable insights into the structures and dynamical aspects of these materials. In particular, NMR analysis has been 
exceptionally crucial for materials that lose their long range order after thermal treatments, which include most borohydrides. Approaches based on nano-engineering have gained growing attention [3, 4] since majority of solid state chemical reactions show poor kinetics due to slow mass transport limitations. Numerous studies by NMR appeared [5, 6] along this line in the recent literature.

The present authors had been part of the research task force for the US-DOE metal hydrides Center of Excellence (MHCoE) [7], and participated in several collaborative efforts applying systematic solid state NMR characterizations of the hydrogenation and dehydrogenation reactions for diverse complex metal hydrides. The present work targets some of the important analytical aspects of solid state NMR spectroscopy for formation and decomposition of these hydrogen storage materials.

In particular, NMR characterization of metal borohydrides is emphasized. Borohydrides often melt and form amorphous phases during the course of hydrogen desorption reactions, limiting the access of conventional X-ray and neutron crystallographic techniques, and progress in multiple steps till the completion of hydrogen discharge. Therefore, ${ }^{11} \mathrm{~B}$ magic angle spinning (MAS) NMR has been a choice for studying metal borohydrides.

\section{Results and Discussion}

One of the key contributions from ${ }^{11} \mathrm{~B}$ NMR is the identification of dodecaborane $\left(\left[\mathrm{B}_{12} \mathrm{H}_{12}\right]^{2-}\right)$ as a stable reaction intermediate[8] generated in borohydrides thermal decompositions. Although the formation of dodecaborane was previously predicted theoretically [9] and experimentally detected by Raman [10] for the $\mathrm{LiBH}_{4}$ case, the NMR confirmation over several borohydrides truly triggered intensive attention in the community and subsequent publications [11-14].

Depending on the reaction conditions, where the hydrogen back pressure appears to be a factor influencing, $\mathrm{B}_{12} \mathrm{H}_{12}$ species could form dominantly.

For example, $\mathrm{Mg}\left(\mathrm{BH}_{4}\right)_{2}$, one of the promising hydrogen storage material showing reversibility up to 11 wt\% [15], was found to form $\mathrm{MgB}_{12} \mathrm{H}_{12}$ before reaching final hydrogen-free decomposition product $\mathrm{MgB}_{2}$ [16].
At the early stage of NMR studies in the literature [8] peaks appearing at $-12 \mathrm{ppm}$ in ${ }^{11} \mathrm{~B}$ MAS NMR (Fig. 1-a) were attributed to $\mathrm{MB}_{12} \mathrm{H}_{12}$ species although the NMR shift from $\mathrm{K}_{2} \mathrm{~B}_{12} \mathrm{H}_{12}$ occurred at $-15.6 \mathrm{ppm}$ when measured as reference material. Besides the shift difference, all other NMR data including ${ }^{11} \mathrm{~B}$ cross polarization (CP) MAS and a $\mathrm{B}-\mathrm{H}$ distance measurement support the assignment. Because of material's heterogeneous nature associated with different metal ions and significant line broadening due to amorphous phase of the material, the shift of 3-4 ppm did not appear to have been seriously taken account. When synthetic capability was extended to numerous alkali and alkali-earth metals, we further examined ${ }^{11} \mathrm{~B}$ NMR shift of $\mathrm{M}_{\mathrm{x}} \mathrm{B}_{12} \mathrm{H}_{12}(\mathrm{M}=2$ or 1 for alkali and alkali earth metals, respectively) and concluded that the shift near at -15.6 ppm show very minor dependence on metal cations [14]. Actual identity of the $-12 \mathrm{ppm}$ peak was better understood when well dehydrated $\mathrm{Li}_{2} \mathrm{~B}_{12} \mathrm{H}_{12}$ was treated in the similar reaction condition that had been used for $\mathrm{LiBH}_{4}$ desorption process. The ${ }^{11} \mathrm{~B}$ peak shifted to $-12 \mathrm{ppm}$ (see Fig. 1-b). Note, however, that release of one $\mathrm{H}_{2}$ molecule per $\mathrm{Li}_{2} \mathrm{~B}_{12} \mathrm{H}_{12}$ was observed, indicating a chemical reaction and consequent structural change on $\mathrm{Li}_{2} \mathrm{~B}_{12} \mathrm{H}_{12}$. The material became water insoluble at room temperature in contrast to high water solubility of neat $\mathrm{Li}_{2} \mathrm{~B}_{12} \mathrm{H}_{12}$. While we are unable to identify the exact structure at the moment, it is likely that $\mathrm{Li}_{2} \mathrm{~B}_{12} \mathrm{H}_{12}$ transforms to form dimer or trimer after loss of $\mathrm{H}_{2}$. Such transformation appears to require heating at temperatures above $450{ }^{\circ} \mathrm{C}$. For borohydrides that require low temperature treatments, such as $\mathrm{Ca}\left(\mathrm{BH}_{4}\right)_{2},{ }^{11} \mathrm{~B}$ MAS NMR reveals the intermediate peak at near -15 ppm [17], and further demonstrating that the dodecaboranes first form and undergo transformation. The heated $\mathrm{Li}_{2} \mathrm{~B}_{12} \mathrm{H}_{12}$ was then treated for hydrogenation reaction under 100 bar $\mathrm{H}_{2}$ and at $450{ }^{\circ} \mathrm{C}$, and ${ }^{11} \mathrm{~B}$ MAS NMR is shown in Fig. 1-c. As expected, sharp peak at $-15.6 \mathrm{ppm}$ appears as a result of the recovery of $\mathrm{Li}_{2} \mathrm{~B}_{12} \mathrm{H}_{12}$.

In an accurate sense, it is certainly more likely that the -12 ppm peak should be assigned to a $\left[\mathrm{B}_{12} \mathrm{H}_{12}\right]$ adduct. Note as well that such finding does not change the conclusion for significant $\left[\mathrm{B}_{12} \mathrm{H}_{12}\right]$ formation in borohydrides during these thermal desorption experiments. 


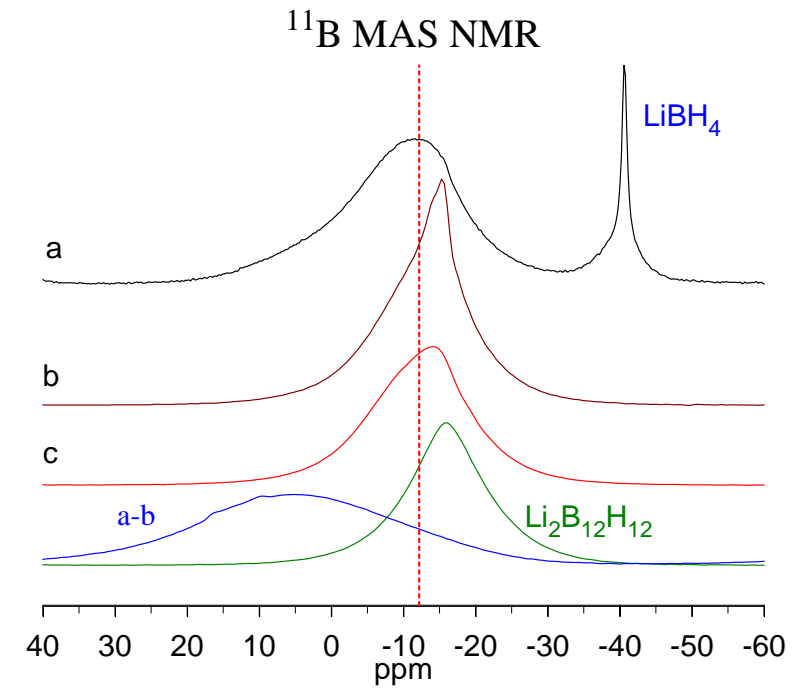

Fig. 1. ${ }^{11} B$ MAS NMR spectra recorded at a Bruker DSX-500 and using a $4 \mathrm{~mm}$ boron-free MAS probe. a) $\mathrm{LiBH}_{4}$ after desorption at $500{ }^{\circ} \mathrm{C}$, b) after hydrogenation of the heated $\mathrm{Li}_{2} \mathbf{B}_{12} \mathrm{H}_{12}$ (sample c), c) $\mathrm{Li}_{2} \mathrm{~B}_{12} \mathrm{H}_{12}$ after heating at $450{ }^{\circ} \mathrm{C}\left(\omega_{\mathrm{r}}\right.$ $=15 \mathrm{kHz})$.

Another interesting observation during the course of these studies of borohydrides is as follows. An ${ }^{11} \mathrm{~B}$ MAS NMR spectrum is typically acquired with strong ${ }^{1} \mathrm{H}$ decoupling pulse following a short rf pulse on the ${ }^{11} \mathrm{~B}$ channel. Because of high dynamical aspect of $\mathrm{BH}_{4}$ units, ${ }^{11} \mathrm{~B}\left\{{ }^{1} \mathrm{H}\right\}$ Nuclear Overhauser Effect (NOE) enhancement is often observed in solid state as Ashbrook et al [18] reported for borane adducts such as $\mathrm{BH}_{3}-\mathrm{PPh}_{3}$. The enhancement becomes noticeable when ${ }^{11} \mathrm{~B}$ signal appears stronger at shorter recycle delay time. Figure 2-a shows the simple test. A transient NOE technique was employed to measure the NOE enhancement, $\eta=\left[I-I_{0}\right] / I_{0}$, of borohydrides we studied, and Fig. 2-b shows $\eta$ of $\mathrm{Mg}\left(\mathrm{BH}_{4}\right)_{2}$ compound as an example at two different temperatures. The efficiency reaches over $40 \%$ at room temperature and drastically decreases at higher temperature as the elevated $\mathrm{BH}_{4}$ motion interfere the $\mathrm{B}-\mathrm{H}$ dipole coupling. The signal enhancement observed for borohydrides is not as big as $155 \%$ of $\mathrm{BH}_{3}-\mathrm{PPH}_{3}$ [18], but certainly could become a crucial factor as ${ }^{11} \mathrm{~B}$ MAS NMR is used for quantitation of boron species. Quantities of boron species containing no hydrogen or lack of mobility would be under estimated. While ${ }^{11} \mathrm{~B}$ MAS NMR spectrum without ${ }^{1} \mathrm{H}$ decoupling could be a choice for avoiding the improper quantitation, the resolution is often greatly reduced for those moieties bearing $\mathrm{B}-\mathrm{H}$ bonds.
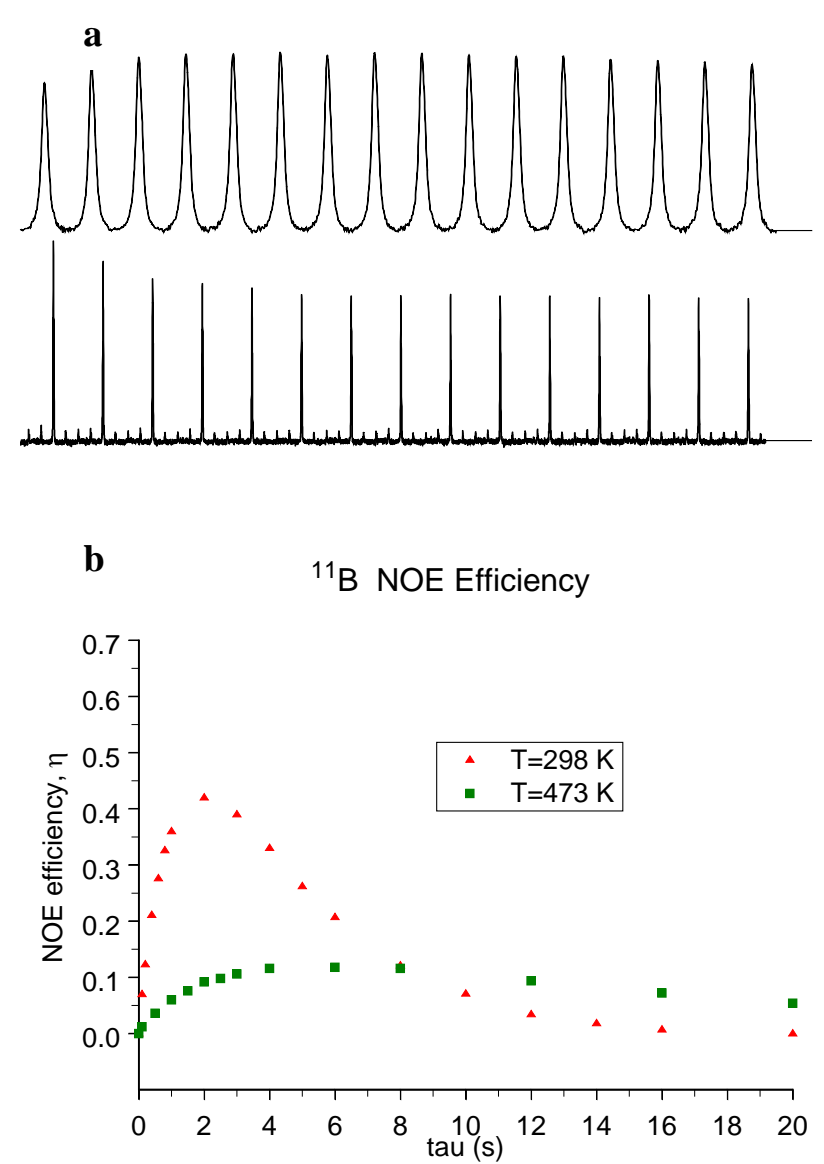

Fig. 2. A) top- ${ }^{11} \mathrm{~B}$ NMR spectra of $\mathrm{Mg}\left(\mathrm{BH}_{4}\right)_{2}$ without ${ }^{1} \mathrm{H}$ decoupling, bottom-with decoupling as the recycle delay time was increased. B) NOE efficiency measured at two different temperatures.

In summary it is demonstrated that solid state NMR methods offer valuable analytical power in accessing solid state chemistry of hydrogen storage materials. Among many diversified area, use of ${ }^{11} \mathrm{~B}$ MAS NMR, in particular, for studies of metal borohydrides was selected as an example. ${ }^{11} \mathrm{~B}\left\{{ }^{1} \mathrm{H}\right\}$ NOE enhancement observed for borohydrides has not been well explored and been ignored in the past literature.

\section{Acknowledgement}

Authors thank Dr. V. Stavila at Sandia National Laboratory for providing many borohydrides materials. This research was supported by the U.S. Department of Energy (DOE), Office of Energy Efficiency and Renewable Energy, through the Hydrogen, Fuel Cells \& 
Infrastructure Technologies Program under contract numbers DE-AI-01-05EE11105 (JPL-Caltech). The NMR facility at Caltech was supported by the National Science Foundation (NSF) under Grant Number 9724240 and partially supported by the MRSEC Program of the NSF under Award Number DMR-520565.

\section{References}

1. Orimo, S. -i.; Nakamori, Y.; Eliseo, J. R.; Zuttel, A.; Jensen, C. M. Complex Hydrides for Hydrogen Storage. Chem. Rev. 2007, 107, 4111-4132.

2. Satyapal, S.; Petrovic, J.; Read, C.; Thomas, G.; Ordaz, G. The U.S. Department of Energy's National Hydrogen Storage Project: Progress towards meeting hydrogenpowered vehicle requirements. Catalysis Today 2007, 120, 246-256.

3. Vajo, J. Influence of nano-confinement on the thermodynamics and dehydrogenation kinetics of metal hydrides. Curr. Opin. Solid State Mater. Sci. 2010, 15, 52-61.

4. Adelhelm, P.; de Jongh, P. E. The impact of carbon materials on the hydrogen storage properties of light metal hydrides. J. Mater. Chem. 2011, 21, 2417-2427.

5. Verkuijlen, M. H. W.; Gao, J.; Adelhelm, P.; van Bentum, P. J. M.; de Jongh, P. E.; Kentgens, A. P. M. Solid-State NMR Studies of the Local Structure of $\mathrm{NaAlH}_{4} / \mathrm{C}$ Nanocomposites at Different Stages of Hydrogen Desorption and Rehydrogenation. J. Phys. Chem. C 2010, 114, 4683-4692.

6. Adelhelm, P.; Gao, J.; Verkuijlen, M. H. W.; Rongeat, C.; Herrich, M.; van Bentum, P. J. M.; Gutfleisch, O.; Kentgens, A. P. M.; de Jong, K. P.; de Jongh, P. E. Comprehensive Study of Melt Infiltration for the Synthesis of NaAlH4/C Nanocomposites. Chem. Mater. 2010, 22, 2233-2238.

7. http://www.sandia.gov/MHCoE/

8. Hwang, S. -J.; Bowman, R. C.; Reiter, J. W.; Rijssenbeek; Soloveichik, G. L.; Zhao, J.-C.; Kabbour, H.; Ahn, C. C. NMR Confirmation for Formation of $\left[\mathrm{B}_{12} \mathrm{H}_{12}\right]^{2-}$ Complexes during Hydrogen Desorption from Metal Borohydrides. J. Phys. Chem. C 2008, 112, 3164-3169.

9. Ohba, N.; Miwa, K.; Aoki, M.; Noritake, T.; Towata, S. -i.; Nakamori, Y.; Orimo, S. -i.; Zuttel, A. First-principles study on the stability of intermediate compounds of LiBH[sub 4]. Phys. Rev. B (Condens. Matter Mater. Phys.) 2006, 74, 075110-7.

10. Orimo, S. -I.; Nakamori, Y.; Ohba, N.; Miwa, K.; Aoki, M.; Towata, S. -i.; Zuttel, A. Experimental studies on intermediate compound of LiBH[sub 4]. Appl. Phys. Lett. 2006, 89, 021920-3.

11. Ozolins, V.; Majzoub, E. H.; Wolverton, C. First-
Principles Prediction of Thermodynamically Reversible Hydrogen Storage Reactions in the Li-Mg-Ca-B-H System. J. Am. Chem. Soc. 2009, 131, 230-237.

12. Her, J. -H.; Yousufuddin, M.; Zhou, W.; Jalisatgi, S. S.; Kulleck, J. G.; Zan, J. A.; Hwang, S. -J.; Bowman, R. C.; Udovic, T. J. Crystal Structure of $\mathrm{Li}_{2} \mathrm{~B}_{12} \mathrm{H}_{12}$ : a Possible Intermediate Species in the Decomposition of $\mathrm{LiBH}_{4}$. Inorg. Chem. 2008, 47, 9757-9759.

13. Friedrichs, O.; Remhof, A.; Hwang, S. J.; ZuÌ̀ttel, A. Role of $\mathrm{Li}_{2} \mathrm{~B}_{12} \mathrm{H}_{12}$ for the Formation and Decomposition of $\mathrm{LiBH}_{4}$. Chem. Mater. 2010, 22, 3265-3268.

14. Stavila, V.; Her, J. -H.; Zhou, W.; Hwang, S. -J.; Kim, C.; Ottley, L. A. M.; Udovic, T. J. Probing the structure, stability and hydrogen storage properties of calcium dodecahydro-closo-dodecaborate. J. Solid State Chem. 2010, 183, 1133-1140.

15. Severa, G.; Ronnebro, E.; Jensen, C. M. Direct hydrogenation of magnesium boride to magnesium borohydride: demonstration of $>11$ weight percent reversible hydrogen storage. Chem. Commun. 2010, 46, 421-423.

16. Soloveichik, G. L.; Gao, Y.; Rijssenbeek, J.; Andrus, M.; Kniajanski, S.; Bowman Jr, R. C.; Hwang, S. -J.; Zhao, J. C. Magnesium borohydride as a hydrogen storage material: Properties and dehydrogenation pathway of unsolvated $\mathrm{Mg}\left(\mathrm{BH}_{4}\right)_{2}$. Int. J. Hydrog. Energy 2009, 34, 916-928.

17. Bonatto Minella, C.; Garroni, S.; Olid, D.; Teixidor, F.; Pistidda, C.; Lindemann, I.; Gutfleisch, O.; BaroÌ $\square$, M. D.; Bormann, R. d.; Klassen, T.; Dornheim, M. Experimental Evidence of $\mathrm{Ca}\left[\mathrm{B}_{12} \mathrm{H}_{12}\right]$ Formation During Decomposition of a $\mathrm{Ca}\left(\mathrm{BH}_{4}\right)_{2}+\mathrm{MgH}_{2}$ Based Reactive Hydride Composite. J. Phys. Chem. C 2011, 115, 18010-18014.

18. Ashbrook, S. E.; Dowell, N. G.; Prokes, I.; Wimperis, S. Nuclear Overhauser Effect (NOE) Enhancement of ${ }^{11} \mathrm{~B}$ NMR Spectra of Borane Adducts in the Solid State. J. Am. Chem. Soc. 2006, 128, 6782-6783. 